\title{
Aspergillosis of the Central Nervous System Causing Subarachnoid Hemorrhage from Mycotic Aneurysm of the Basilar Artery -Case Report-
}

\author{
Koji IIHARA, Yasumasa MaKiTA, Sachio NABESHIMA, Taikyoku TEI, \\ Atsushi KEYAKI and Hirofumi NIOKA
}

Department of Neurosurgery, Tenri Hospital, Tenri, Nara

\begin{abstract}
The authors present an extremely rare case of aspergillosis of the central nervous system (CNS) causing subarachnoid hemorrhage (SAH). A 78-year-old female developed facial pain, progressive deterioration in left visual acuity, and left total ophthalmoplegia. Computed tomography demonstrated a heterogeneously enhanced mass extending from the sphenoid sinus to the left cavernous sinus and left orbit, and angiography showed luminal narrowing and irregularity of the left internal carotid artery at its siphon. Biopsy of the left orbital and sphenoid sinus mass resulted in the diagnosis of Aspergillus granuloma. Despite combined administration of amphotericin-B and 5-FC, she became comatose from brainstem infarction and finally, suddenly died. Postmortem examination revealed massive SAH due to a ruptured mycotic aneurysm of the basilar artery. Aspergillosis of the CNS is a growing problem with the wider use of immunosuppressants and antibiotics. To the authors' knowledge, however, only 13 cases of CNS aspergillosis causing SAH have been reported. The prognosis is absolutely bad, with all patients dying from rupture of major intracranial arteries such as the internal carotid artery and basilar artery. Early diagnosis and vigorous chemotherapy are important.
\end{abstract}

Key words: Aspergillus, subarachnoid hemorrhage, brainstem infarction, mycotic aneurysm

\section{Introduction}

Aspergillosis of the central nervous system (CNS) is a relatively rare disease, but recently has increased in frequency with the wider use of antibiotics, steroids, and immunosuppressants. ${ }^{16,20)}$ However, to our knowledge only 13 cases that developed subarachnoid hemorrhage (SAH) have been reported. . $^{1,2,4,5,8-}$ $11,14,15,18-20)$ We report such a case of a 78 -year-old female, who developed decreased vision, ocular movement disturbance, and facial pain, and finally died of SAH during treatment.

\section{Case Report}

A 78-year-old female had been healthy until February, 1988, when she developed left facial pain and was administered an analgesic agent by a local physician. From July, 1988, she experienced progressive decreased vision of the left eye, and also suffered ptosis on the same side 2 months later. She was admitted to Tenri Hospital with abnormalities demonstrated by computed tomography (CT) and magnetic resonance (MR) imaging.

On admission, she was alert and afebrile. Neurological examination revealed visual loss, ptosis, and almost complete total ophthalmoplegia, all on the left side. Her right visual acuity was also diminished to $0.1(0.2)$. Facial pain, corresponding to the region of the 1st branch of the left trigeminal nerve, was noted. Exophthalmos was not observed. Laboratory examination showed mild leukocytosis $\left(8800 / \mathrm{mm}^{3}\right)$ and a slight increase in C-reactive protein $(0.4 \mathrm{mg} /$ dl) (normal, $<0.2 \mathrm{mg} / \mathrm{dl}$ ). The tuberculin test was

Received August 17, 1989; Accepted March 28, 1990 Author's present address: K. Ihara, M.D., Department of Neurosurgery, Shizuoka General Hospital, Shizuoka, Japan. 
pseudopositive, and the lymphocyte blastogenesis test revealed a slight decline in cellular immunity.

Skull $x$-rays and tomograms of the sella turcica revealed destruction of the left anterior clinoid process, erosion of the left superior orbital fissure, and soft-tissue density in the sphenoid sinus (Fig. 1). The chest $\mathrm{x}$-ray was normal. Postcontrast CT scans demonstrated a heterogeneously enhanced, isodense lesion extending from the sphenoid sinus into the left orbit and left cavernous sinus (Fig. 2). $\mathrm{T}_{1}$ weighted MR images showed an isointense lesion that was heterogeneously enhanced with gadoliniumdiethylenetriaminepenta-acetic acid and surrounded the left internal carotid artery (Fig. 3). Digital subtraction angiograms demonstrated irregularity and luminal narrowing at the $\mathrm{C}_{3}-\mathrm{C}_{4}$ portion of the left internal carotid artery. No aneurysms were detected.

After admission, her right visual acuity gradually diminished and the light reflex finally disappeared, but immediate administration of steroids restored

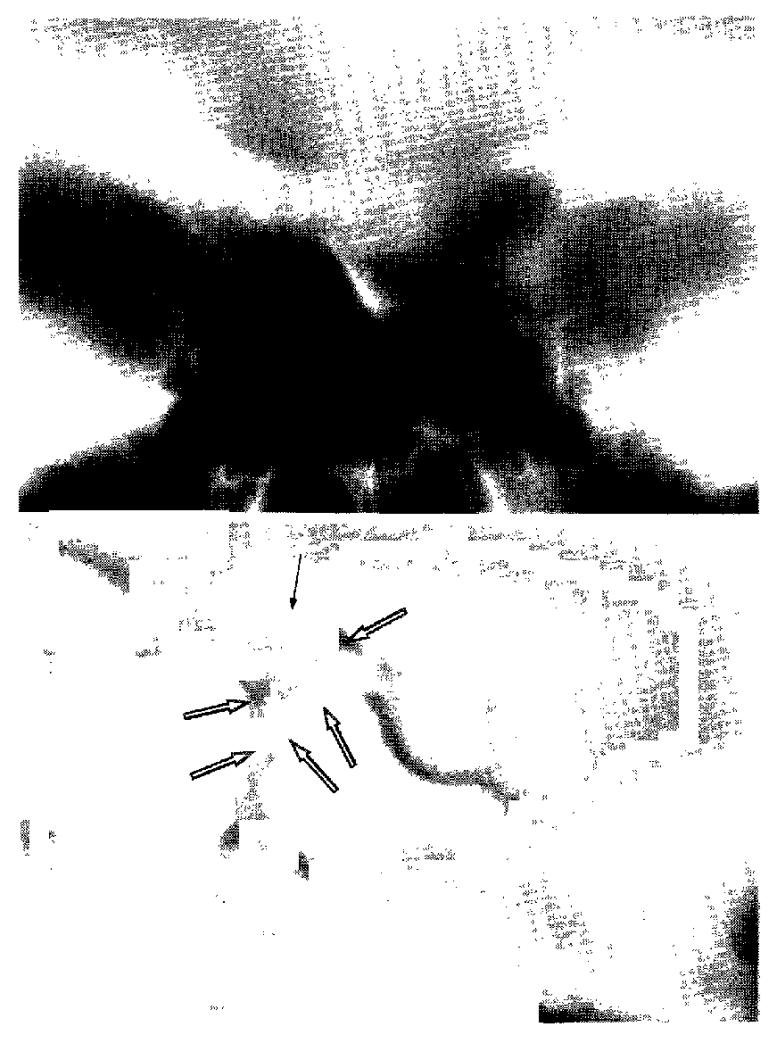

Fig. 1 Polytomograms of the sellar region. upper: Coronal section, showing a cloudy sphenoid sinus and destruction and enlargement of the left superior orbital fissure. lower: Sagittal section, revealing a solid mass (arrows) in the anterosuperior portion of the sphenoid sinus and erosion of the planum sphenoidale.
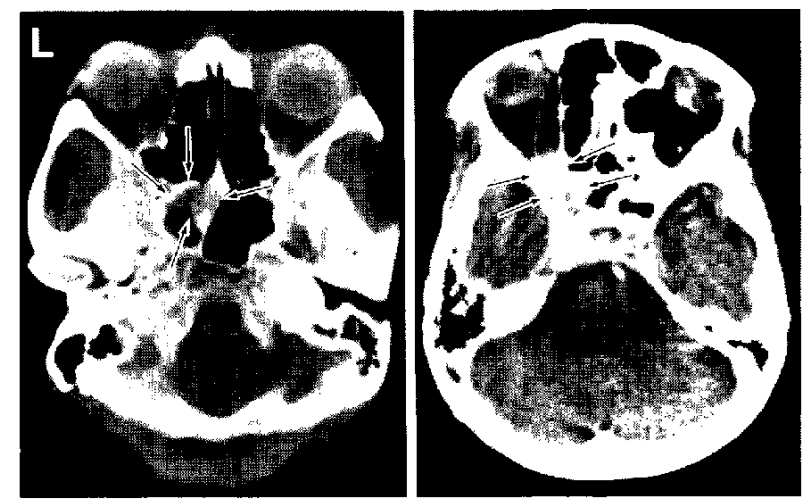

Fig. 2 Preoperative CT scans, left: A solid mass (arrows) occupies the left half of the sphenoid sinus (bone window). right: The mass (arrows) is heterogeneously enhanced and extends to the left cavernous sinus and the left orbit.

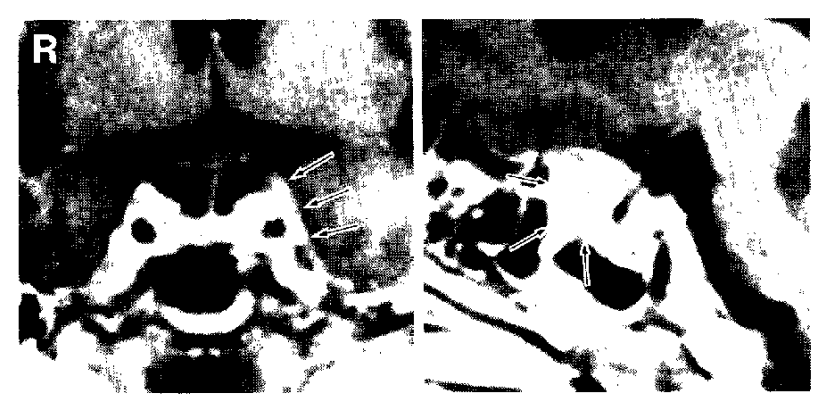

Fig. 3 Preoperative MR images. left: Coronal section, demonstrating the mass (arrows) extending from the left cavernous sinus into the suprasellar cistern, and involvement and luminal narrowing of the left internal carotid artery. right: Sagittal section, showing the left internal carotid artery surrounded by the mass (arrows) at its siphon, cavernous part, and ganglial part.

the vision to the level on admission by the next day. On November 14, with a diagnosis of malignant tumor originating from the paranasal sinus, she was referred to an otolaryngologist for a biopsy under local anesthesia. Incision of the optic canal via the paranasal cavity by Killian's approach revealed that the canal was filled with greenish-yellow material and a very small quantity of pus was exuded from that region. Therefore, the operation was not continued beyond extirpating a part of the mass in the orbit. $\mathrm{HE}$ staining of the surgical specimen revealed $\mathrm{Y}$ shaped hyphae in the granulation tissue. This finding, together with the results of culture of the pus led to a histological diagnosis of granuloma due to 


\section{Aspergillus fumigatus.}

Intravenous administration of amphotericin-B (the daily dose increased gradually from 1 to $25 \mathrm{mg}$ ), combined with oral administration of 5-FC, was started on November 19. Since, however, the neurological symptoms did not improve, the sphenoid sinus, which was considered to be the entrance of the infection, was incised via the left nasal cavity on December 2. The mucous membrane was thickened and pulsating. After extirpating the mass in the upper part of the sphenoid sinus, a Nelaton catheter was inserted. The histological findings were the same as for the previous operation.

Local administration of amphotericin-B via the Nelaton catheter was given additionally. On December 10, dyspnea suddenly occurred, but was relieved by administration of diuretics. Because myocarditis was suspected by electro- and echocardiograms, the administration of 5-FC only was continued. However, she fell into a semicoma on December 16. CT scans revealed a low-density area in the midbrain, bilateral thalami, and left parietal lobe, so the consciousness disturbance was thought to be due to the midbrain infarction (Fig. 4). Examination of the cerebrospinal fluid (CSF) showed pleocytosis and an increased protein content, indicating complications with meningitis. CSF culture was negative, but intrathecal injection of amphotericin- $B$ and antibiotics was started. Thereafter, the respiration and vital signs were stable, although the consciousness disturbance did not improve. However, she was found in a cardiac arrest at midnight on January 10, 1989.

A general autopsy performed the same day revealed massive $\mathrm{SAH}$ extending from the posterior fossa to the base of the brain, and accompanied by intraventricular hemorrhage. The left internal carotid

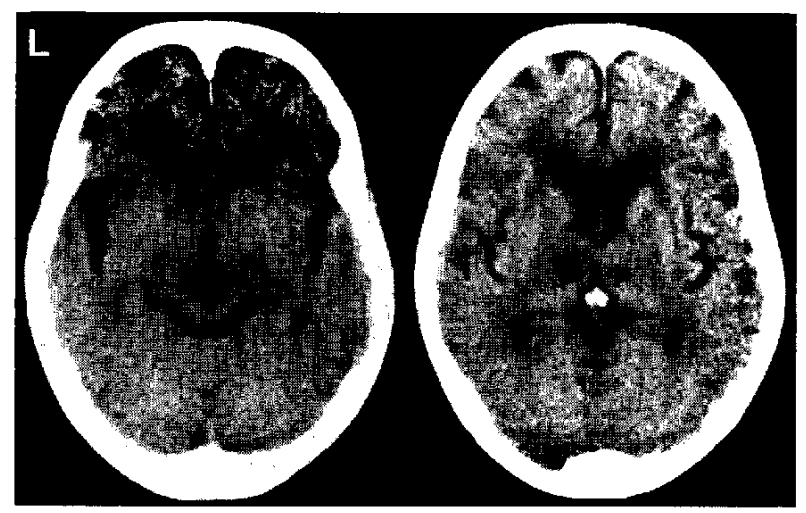

Fig, 4 Precontrast CT scans 3 days after acute deterioration, revealing infarction in the midbrain, bilateral thalami, and left caudate head.

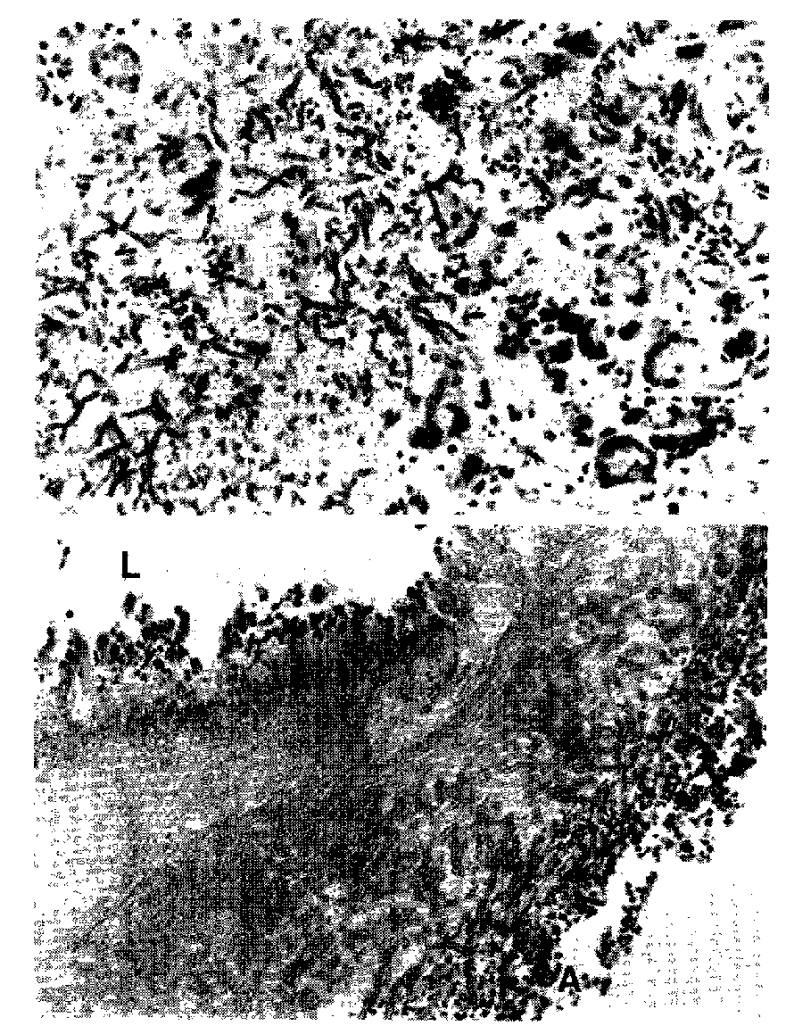

Fig. 5 Photomicrographs of the autopsy specimen. upper: The section from the sphenoid sinus mass, demonstrating multinucleated giant cells and numerous branching hyphae. HE stain, $\times 200$. lower: The section from the top of the basilar artery, showing invasion of numerous Aspergillus hyphae into the vessel wall and formation of a mycotic aneurysm. L: lumen, A: adventitia. HE stain, $\times 200$.

artery was enclosed by the granuloma and had a narrowed lumen. The planum sphenoidale was thinned and the granuloma protruded from the left cavernous sinus into the basal cistern. No distinct spread of inflammation to the cerebral parenchyma was seen. The meninges at the base of the brain were thickened. A hematoma was firmly adhered to the tip of the basilar artery. Histological examination revealed an Aspergillus granuloma, consisting of giant and epithelioid cells, proliferating invasively and mainly in the sphenoid and left cavernous sinuses, and extending to the area around the left optic nerve (Fig. 5). Invasion of Aspergillus, seen in the left internal carotid artery as well, was accompanied by formation of thrombus. At the tip of the basilar artery, infiltration of Aspergillus into the vascular wall formed a mycotic aneurysm, which was thought to be the source of hemorrhage. Infarc- 
tion was noted in the basal ganglia, thalamus, midbrain, and centrum semiovale. No distinct lesion was observed in other systemic organs.

\section{Discussion}

The incidence of aspergillosis of the CNS has increased with the wider use of antibiotics, steroids, and immunosuppressants in recent years. ${ }^{16,20)}$ Since Oppe's first report in 1897, more than 170 cases have been reported. ${ }^{2)}$ Mukoyama et al. ${ }^{13)}$ roughly classified the mode of development into five types, namely, 1) meningitis, 2) meningoencephalitis, 3) abscess, 4) granuloma, and 5) vasculitis; brain abscess was the most common, accounting for 20 of 33 cases, followed by meningitis and meningoencephalitis.

Aspergillosis of the CNS is often found in males and is said to be unrelated to age. It often develops in patients with debilitating diseases such as tuberculosis, cancer, leukemia, and alcoholism. ${ }^{13,20)}$ The routes of entry into the CNS have been reported to be: 1) circulatory propagation from other organs such as lungs; 2) direct invasion from the adjacent skull regions such as the middle ear cavity, paranasal sinus, and orbit; and rarely 3 ) brain surgery, lumbar puncture, and blood transfusion. ${ }^{13,16)}$ In our case, granuloma was present in the sphenoid sinus, left orbit, and left parasellar region. Mukoyama et al. ${ }^{13)}$ summarized 33 cases of aspergillosis of the CNS and found paranasal lesions in nine, in which only one was sphenoid sinus. On the other hand, aspergillosis in the orbit mostly originated from the paranasal cavity and presented with exophthalmos. However, exophthalmos is sometimes absent in cases with short clinical courses, ${ }^{2,7}$ as in our case. In the present case, no distinct underlying disease was observed, but a mild decline in cellular immunity was demonstrated. The Aspergillus in the sphenoid sinus presumably developed in the orbit and intracranial cavity because of some decrease in cellular immunity.

Despite recent progress in neuroradiology, aspergillosis of the CNS is still difficult to diagnose. ${ }^{20)} \mathrm{CT}$ scans show non-specific findings such as non-enhanced, low-density areas and ring-like enhancement. ${ }^{3,6)}$ Recently, Tsuboi et al. ${ }^{17)}$ reported $0.15-\mathrm{T}$ MR findings for Aspergillus granuloma. Using a 1.5-T MR scanner, we found the lesion to be isosignal intensity on a $T_{1}$-weighted image and highsignal intensity on a $T_{2}$-weighted image. Therefore, it is difficult, even with MR imaging, to differentiate this disease from other lesions, particularly malignant nasopharyngeal tumors. However, MR images clearly revealed the encasement of the left internal carotid artery by the mass, which was useful for determining the therapeutic policy and predicting the prognosis.

An established diagnosis of this rare disease can be made only by biopsy and culture of the resected specimen. ${ }^{16,21)}$ CSF analysis revealed pleocytosis and an increased protein content, but CSF culture was negative in many cases. ${ }^{13,20)}$ Serological examinations, such as the serum sedimentation and complement fixation tests, have been used in recent years, ${ }^{16)}$ but do not yet have adequate sensitivity.

Treatment of Aspergillus infection is very unsatisfactory at present. Radical resection and combined chemotherapy with amphotericin-B, 5-FC, and rifampicin are available. ${ }^{20)}$ However, administration of amphotericin-B must be discontinued in many cases because of serious side effects. Sekhar et $a{ }^{16)}$ have reported a case, in which treatment with amphotericin-B and rifampicin failed to obtain satisfactory results but succeeded by changing the medication from rifampicin to 5-FC, emphasizing the importance of the in-vitro sensitivity test. In our case, the progress in diminution of the right vision was arrested to some extent by postoperative administration of amphotericin-B and 5-FC, however, administration of the former had to be discontinued because of myocarditis and the subsequent deterioration in general condition.

The prognosis for aspergillosis of the CNS is very poor, with the mortality reaching $80 \%$. ${ }^{7}$ The key to effective treatment is the recognition of the underlying disease and early diagnosis. ${ }^{20}$

To our knowledge, only 13 cases of CNS aspergillosis which developed SAH have been reported ${ }^{1,2,4,5,8-}$ ${ }_{11,14,15,18-20)}$ (Table 1). It is well known that Aspergillus causes vasculitis. According to Horten et al., ${ }^{81}$ vasculitis can follow three courses: 1) formation of thrombus, causing hemorrhagic infarction and brain abscess; 2) sudden massive hemorrhage; and 3) formation of an aneurysm. Fungal aneurysms are said to be different from bacterial aneurysms in that they are often found in the major vessels at the base of the brain, and their developmental mechanism is more often by direct invasion from the luminal surface and the adventitia than by involvement of the vasa vasorum. ${ }^{8}{ }^{82)}$ Our case also showed involvement of the left internal carotid artery, with the stenosed lumen, by the granulation tissue. The autopsy revealed no distinct focus in other organs. In the present case, therefore, it seems likely that Aspergillus granuloma in the sphenoid sinus spread to the left cavernous sinus and internal carotid artery, and then extended continuously to the base of the brain, 
Table 1 Aspergillosis of the CNS causing SAH

\begin{tabular}{|c|c|c|c|c|c|c|}
\hline $\begin{array}{l}\text { Case } \\
\text { No. }\end{array}$ & Author (Year) & $\begin{array}{l}\text { Age/ } \\
\text { Sex }\end{array}$ & $\begin{array}{l}\text { Possible predisposing } \\
\text { factors }\end{array}$ & $\begin{array}{l}\text { Initial neurological } \\
\text { manifestations }\end{array}$ & Aneurysm site & $\begin{array}{l}\text { Other neuropathological } \\
\text { findings }\end{array}$ \\
\hline 1 & McKee $(1950)^{103}$ & $60 / \mathrm{M}$ & heart disease, sinusitis & $\begin{array}{l}\text { headache, sudden } \\
\text { collapse }\end{array}$ & none & ruptured ICA \\
\hline 2 & $\begin{array}{l}\text { Davidson and Robertson } \\
(1971)^{4)}\end{array}$ & $75 / \mathrm{M}$ & $\begin{array}{l}\text { azotemia, sinusitis, } \\
\text { cholecystectomy }\end{array}$ & sudden coma & $\begin{array}{l}\text { basilar } \\
\text { artery }\end{array}$ & IVH \\
\hline 3 & $\begin{array}{l}\text { Visudhiphan et al. } \\
(1973)^{18)}\end{array}$ & $13 / \mathrm{M}$ & $\begin{array}{l}\text { surgery for craniopharyn- } \\
\text { gioma }\end{array}$ & & $\begin{array}{l}\text { basilar } \\
\text { artery }\end{array}$ & \\
\hline 4 & $\begin{array}{l}\text { Sakaki et al. } \\
\qquad(1975)^{157}\end{array}$ & $26 / \mathrm{M}$ & craniotomy for AVM & & lt ICA & \\
\hline 5 & Horten et al. $(1976)^{81}$ & $17 / \mathrm{F}$ & open heart surgery & $\begin{array}{l}\text { headache, seizures, } \\
\text { It hemiplegia }\end{array}$ & $\begin{array}{l}\text { rt } \mathrm{MCA}, \\
\text { rt calloso- } \\
\text { marginal } \\
\text { artery }\end{array}$ & $\begin{array}{l}\text { IVH, hemorrhagic necrosis } \\
\text { of it frontal lobe }\end{array}$ \\
\hline 6 & Ahuja et al. (1978)" & $18 / \mathrm{M}$ & $\begin{array}{l}\text { sinusitis, nasal } \\
\text { polypectomy }\end{array}$ & $\begin{array}{l}\text { headache, fever, } \\
\text { coma, convulsion }\end{array}$ & rt PComA & $\begin{array}{l}\text { IVH, rt MCA territory } \\
\text { infarction }\end{array}$ \\
\hline 7 & $\begin{array}{l}\text { Mielke et al. } \\
(1981)^{(1)}\end{array}$ & $58 / \mathrm{F}$ & $\begin{array}{l}\text { trans-sphenoidal surgery } \\
\text { for acromegaly }\end{array}$ & $\begin{array}{l}\text { blindness, headache, } \\
\text { ophthalmoplegia }\end{array}$ & $\begin{array}{l}\text { basilar } \\
\text { artery, } \\
\text { 1t ICA }\end{array}$ & $\begin{array}{l}\text { chronic meningitis and } \\
\text { vasculitis }\end{array}$ \\
\hline 8 & $\begin{array}{l}\text { Partridge and Chin } \\
(1981)^{14)}\end{array}$ & $18 / \mathrm{M}$ & sinusitis & $\begin{array}{l}\text { blindness, retro- } \\
\text { orbital pain }\end{array}$ & $\begin{array}{l}\text { yertebral } \\
\text { artery }\end{array}$ & $\begin{array}{l}\text { IVH, lt temporal lobe } \\
\text { infarction }\end{array}$ \\
\hline 9 & $\begin{array}{l}\text { Fernando and Lauer } \\
(1982)^{3 !}\end{array}$ & $56 / \mathrm{M}$ & sinusitis & $\begin{array}{l}\text { blindness, retro- } \\
\text { orbital pain }\end{array}$ & rt ICA & rt temporal lobe infarction \\
\hline 10 & Leeds et al. $(1983)^{9)}$ & $25 / \mathrm{M}$ & drug abuse & $\begin{array}{l}\text { hemiparesis, back } \\
\text { pain }\end{array}$ & $?$ & $\begin{array}{l}\text { infarction in globus } \\
\text { pallidus, } \\
\text { lumbar arachnoiditis }\end{array}$ \\
\hline 11 & Walsh et al. $(1985)^{20)}$ & $64 / F$ & $\begin{array}{l}\text { adrenal adenocarcinoma, } \\
\text { sinusitis }\end{array}$ & $\begin{array}{l}\text { lethargy, rt hemi- } \\
\text { paresis }\end{array}$ & rt PCA & $\begin{array}{l}\text { infarction in occipito- } \\
\text { parietal region }\end{array}$ \\
\hline 12 & Vu et al. $(1986)^{19)}$ & $62 / \mathrm{M}$ & hemodialysis & $\begin{array}{l}\text { lever, lethargy, } \\
\text { seizure, coma }\end{array}$ & rt $\mathrm{ACA}$ & $\begin{array}{l}\text { IVH, rt MCA territory } \\
\text { infarction }\end{array}$ \\
\hline 13 & $\begin{array}{l}\text { Corvisier et al. } \\
(1987)^{21}\end{array}$ & $54 / F$ & $\begin{array}{l}\text { Hodgkin's disease, } \\
\text { sinusitis, steroid } \\
\text { therapy }\end{array}$ & blindness, ptosis & none & ruptured ICA \\
\hline 14 & Present case & $78 / \mathrm{F}$ & sinusitis & $\begin{array}{l}\text { blindness, headache, } \\
\text { ophthalmoplegia }\end{array}$ & $\begin{array}{l}\text { basilar } \\
\text { artery }\end{array}$ & $\begin{array}{l}\text { IVH, brainstem and } \\
\text { thalamic infarction }\end{array}$ \\
\hline
\end{tabular}

A VM: arteriovenous malformation, ICA: internal carotid artery, MCA: middle cerebral artery, PComA: posterior communicating artery, PCA: posterior cerebral artery, ACA: anterior cerebral artery, IVH: intraventricular hemorrhage.

causing vasculitis and thrombosis of the perforators, which resulted in infarction in the thalamus and brainstem.

Ruptured vessels in the reported cases were located at the base of the brain, with four of internal carotid artery, ${ }^{2,5,10,15)}$ three of basilar artery, ${ }^{4,11,18)}$ and one each of anterior cerebral, ${ }^{19)}$ middle cerebral, ${ }^{81}$ posterior cerebral, ${ }^{20)}$ posterior communicating, ${ }^{1)}$ and vertebral arteries. ${ }^{14)}$ Many cases developed massive SAH accompanied by intraventricular hemorrhage, and all the patients died. In our case, the massive SAH was mainly located in the posterior fossa and, judging from the autopsy findings, was caused by rupture of the mycotic aneurysm of the basilar artery.

\section{References}

1) Ahuja GK, Jain N, Vijayaraghavan $M$, Roy $S$ : Cerebral mycotic aneurysm of fungal origin. Case report. $J$ Neurosurg 49: 107-110, 1978
2) Corvisier N, Gray F, Gherardi R, Lebras F, Blanc CM, Nguyen JP, Poirier J: Aspergillosis of ethmoid sinus and optic nerve, with arteritis and rupture of the internal carotid artery. Surg Neurol 28: 311-315, 1987

3) Danziger A, Price H: Computed axial tomography in intracranial aspergillosis. A report of 2 cases. $S \mathrm{Afr}$ Med J 54: 706-708, 1978

4) Davidson P, Robertson DM: A true mycotic (Aspergillus) aneurysm leading to fatal subarachnoid hemorrhage in a patient with hereditary hemorrhagic telangiectasia. Case report. $J$ Neurosurg 35: 71-76, 1971

5) Fernando SSE, Lauer CS: Aspergillus fumigatus infection of the optic nerve with mycotic arteritis of cerebral vessels. Histopathology 6: 227-234, 1982

6) Grossman RI, Davis KR, Taveras JM, Beal MF, O'Carrol CP: Computed tomography of intracranial aspergillosis. J Comput Assist Tomogr 5; 646-650, 1981

7) Hedges TR, Leung LE: Parasellar and orbital apex syndrome caused by aspergillosis. Neurology (Minneap) 26: $117-120,1976$ 
8) Horten BC, Abbott GF, Porro RS: Fungal aneurysms of intracranial vessels. Arch Neurol 33: 577579,1976

9) Leeds NE, Malhotra V, Zimmermann RD: The radiology of drug addiction affecting the brain. Semin Roentgenol 18: 227-233, 1983

10) McKee EE: Mycotic infection of brain with arteritis and subarachnoid hemorrhage. Report of case. Amer $J$ Clin Path 20: 381-384, 1950

11) Mielke B, Weir B, Oldring D, von Westarp C: Fungal aneurysm. Case report and review of the literature. Neurosurgery 9: 578-582, 1981

12) Molinari GF, Smith L, Goldstein MN, Satran R: Pathogenesis of cerebral mycotic aneurysms. Neurology (Minneap) 23: 325-332, 1973

13) Mukoyama M, Gimple K, Poser C: Aspergillosis of the central nervous system. Report of a brain abscess due to A. fumigatus and review of the literature. Neurology (Minneap) 19: 967-973, 1969

14) Partridge BM, Chin ATL: Cerebral aspergilloma. Postgrad Med J 57: 439-442, 1981

15) Sakaki J, Kikuchi H, Furuse K, Kawai S, Karasawa J, Manabe T, Yoshida H, Matsuda H, Honda Y: Case of cerebral aneurysm due to Aspergillus angitis. Rinsho Hoshasen 30: 95-96, 1975 (in Japanese)
16) Sekhar LN, Dujovny M, Rao GR: Carotid-cavernous sinus thrombosis caused by Aspergillus fumigatus. Case report. J Neurosurg 52: 120-125, 1980

17) Tsuboi $K$, Higuchi $O$, Nose $T$, Maki $Y$ : Intracranial Aspergillus granuloma originating in the sphenoidal sinus. Case report. Neurol Med Chir (Tokyo) 28: $1014-1019,1988$

18) Visudhiphan P, Bunyaratavej S, Khantanaphar S: Cerebral aspergillosis. Report of three cases. $J$ Neurosurg 38: 472-476, 1973

19) $\mathrm{Vu} \mathrm{N}$, Kim RC, Choi BH: Aspergillotic cerebral arterial aneurysm formation complicating hemodialysis. Surg Neurol 25: 582-586, 1986

20) Walsh TJ, Hier DB, Caplan LR: Aspergillosis of the central nervous system: Clinicopathological analysis of 17 patients. Ann Neurol 18: 574-582, 1985

21) Yanai $Y$, Wakao T, Fukamachi A, Kunimine H: Intracranial granuloma caused by Aspergillus fumigatus. Surg Neurol 23: 597-604, 1985

Address reprint requests to: K. Iihara, M.D., Department of Neurosurgery, Shizuoka General Hospital, 4-27-1 Kita-ando, Shizuoka 420, Japan. 